\title{
Dexmedetomidine ameliorates intracerebral hemorrhage-induced memory impairment by inhibiting apoptosis and enhancing brain- derived neurotrophic factor expression in the rat hippocampus
}

\author{
LAKKYONG HWANG $^{1}$, IN-YOUNG CHOI ${ }^{1}$, SUNG-EUN KIM ${ }^{1}$, IL-GYU KO ${ }^{1}$, MAL-SOON SHIN ${ }^{1}$, \\ CHANG-JU KIM ${ }^{1}$, SANG-HOON KIM ${ }^{2}$, JUN-JANG JIN ${ }^{3}$, JUN-YOUNG CHUNG ${ }^{4}$ and JAE-WOO YI ${ }^{4}$ \\ ${ }^{1}$ Department of Physiology, College of Medicine, Kyung Hee University, Seoul 130-701; ${ }^{2}$ Department of Physical Education, \\ Graduate School of Education, Sang Myung University, Seoul 110-743; ${ }^{3}$ Department of Physical Activity Design, \\ College of Science, Hanseo University, Seosan 356-706; ${ }^{4}$ Department of Anesthesiology and Pain Medicine, \\ Gangdong Kyung Hee Hospital, College of Medicine, Kyung Hee University, Seoul 134-727, Republic of Korea
}

Received January 27, 2013; Accepted March 8, 2013

DOI: $10.3892 / \mathrm{ijmm} .2013 .1301$

\begin{abstract}
Intracerebral hemorrhage (ICH) is a severe type of stroke causing neurological dysfunction with a high mortality rate. Dexmedetomidine is an agonist for $\alpha_{2}$-adrenoreceptors with sedative, anxiolytic, analgesic and anesthetic effects. In the present study, we investigated the effects of dexmedetomidine on short-term and spatial learning memory, as well as its effects on apoptosis following the induction of ICH in rats. A rat model of IHC was created by an injection of collagenase into the hippocampus using a stereotaxic instrument. Dexmedetomidine was administered intraperitoneally daily for 14 consecutive days, commencing 1 day after the induction of ICH. The step-down avoidance test for short-term memory and the radial 8 -arm maze test for spatial learning memory were conducted. Terminal deoxynucleotidyl transferase-mediated dUTP nick end-labeling (TUNEL) assay, immunohistochemistry for caspase-3, and western blot analysis for Bcl-2, Bax, Bid and caspase-3 expression were performed for the detection of apoptosis in the hippocampus. Western blot analysis for the brain-derived neurotrophic factor (BDNF) and tyrosine kinase B (TrkB) was also performed for the detection of cell survival in the hippocampus. The induction of ICH deteriorated short-term and spatial learning memory, increased apoptosis and suppressed BDNF and TrkB expression in the hippocampus. Treatment with dexmedetomidine ameliorated the ICH-induced impairment of short-term and spatial learning
\end{abstract}

Correspondence to: Professor Jae-Woo Yi, Department of Anesthesiology and Pain Medicine, Gangdong Kyung Hee Hospital, College of Medicine, Kyung Hee University, 892 Dongnam-ro, Gangdong-gu, Seoul 134-727, Republic of Korea

E-mail: mdyjwchk@khu.ac.kr

Key words: $\alpha_{2}$-adrenoreceptors, short-term memory, intracerebral hemorrhage, dexmedetomidine, apoptosis, spatial learning memory memory by suppressing apoptosis and enhancing BDNF and TrkB expression. In the normal rats, dexmedetomidine exerted no significant effects on memory function and apoptosis. The present results suggest the possibility that dexmedetomidine may be used as a therapeutic agent for the conservation of memory function in stroke patients.

\section{Introduction}

Intracerebral hemorrhage $(\mathrm{ICH})$ is a severe type of stroke causing neurological dysfunction with a high mortality rate (1). Current surgical therapies for $\mathrm{ICH}$ are not effective and acceptable drugs have not yet been developed for clinical trials. ICH-induced brain injury occurs through multiple mechanisms, and is also mediated in part by an apoptotic mechanism $(2,3)$.

Apoptosis is a form of cell death that constitutes part of a common mechanism in cell replacement, tissue remodeling, and the removal of damaged cells. Apoptosis is triggered by a variety of stimuli (4); however, the inappropriate or excessive initiation of apoptosis has been implicated in several types of neurodegenerative disorders, including stroke (5). Apoptotic cell death can be assessed using terminal deoxynucleotidyl transferase-mediated dUTP nick end-labeling (TUNEL) staining, which detects DNA fragmentation. The caspases, a family of 14 cysteine proteases, are essential players in apoptotic cell death both as initiators (caspase-2, -8, -9 and -10) and executioners (caspase-3, -6 and -7) (6). Cell death in the parenchyma occurs via apoptotic mechanisms during $\mathrm{ICH}$, and apoptotic cell death is associated with the induction of caspase- 3 in cells adjacent to the hematoma $(2,7)$. Apart from the caspases, the Bcl-2 family proteins also play important roles in the regulation of apoptosis. The Bcl-2 family proteins are classified into anti-apoptotic proteins, including Bcl-2 and Bcl-xL, and pro-apoptotic proteins, such as Bax and Bid. The balance between pro-apoptotic and anti-apoptotic Bcl-2 family members determines the mitochondrial response to apoptotic stimuli (8). 
Brain-derived neurotrophic factor (BDNF) is a small dimeric protein, and functions through its receptor, tyrosine kinase $\mathrm{B}$ (TrkB). BDNF modulates neuronal cell growth and survival, and BDNF has been implicated in learning and memory processes; therefore, dysfunction in BDNF is accompanied by cognitive deficits (9). BDNF enhances hippocampal-dependent memory and long-term potentiation, a form of synaptic plasticity, via TrkB (10). A high level of BDNF is concentrated in the hippocampus, and BDNF expression is selectively increased following activity-dependent learning and memory tasks (11). TrkB activation has been shown to inhibit apoptosis following subarachnoid hemorrhage (12).

Dexmedetomidine is a potent and highly selective agonist for $\alpha_{2}$-adrenoreceptors with sedative, anxiolytic, analgesic and anesthetic effects $(13,14)$. The neuroprotective effects of dexmedetomidine by stimulating $\alpha_{2}$-adrenoreceptors have been reported (15-17). Dexmedetomidine has been shown to inhibit apoptotic neuronal cell death in the hippocampus by enhancing antioxidant activity following transient global cerebral ischemia-reperfusion injury in rats (18). Dexmedetomidine has also been shown to exert neuroprotective effects following subarachnoid hemorrhage-induced hippocampal injury in rabbits (19) and to reduce oxidative stress following subarachnoid hemorrhage in rats (20).

The neuroprotective effects of dexmedetomidine against several brain injuries have been suggested; however, the memory deteriorating effects of dexmedetomidine have also been indicated. Dexmedetomidine infusion results in reversible sedation, mild analgesia and memory impairment (21). Dexmedetomidine impairs long-term potentiation in the mouse hippocampus via activation of $\alpha_{2}$-adrenoreceptors (22). van Oostrom et al (23) reported that the suppressive effect of dexmedetomidine on memory formation occurred at doses which reduce central nervous system activity. In a study on humans, dexmedetomidine-induced amnesia was caused by a failure of information to be encoded into long-term memory (24).

In the present study, we investigated whether dexmedetomidine ameliorates or exacerbates memory function under ICH conditions. For this purpose, a step-down avoidance test for short-term memory and a radial 8 -arm maze test for spatial learning memory were conducted using rats. The anti-apoptotic effect of dexmedetomidine against ICH was also evaluated. Apoptosis in the hippocampus was detected using TUNEL assay, immunohistochemistry for caspase-3, and western blot analysis for Bcl-2, Bax, Bid and caspase-3 expression in the hippocampus. Western blot analysis for BDNF and TrkB was also performed for the detection of cell survival in the hippocampus.

\section{Materials and methods}

Experimental animals and treatments. All experiments were performed in accordance with the Animal Care Guidelines of the National Institutes of Health (NIH) and the Korean Academy of Medical Sciences. The effects of dexmedetomidine on $\mathrm{ICH}$-induced brain injury in rats were evaluated. Seven-week-old Sprague-Dawley rats $(210 \pm 10 \mathrm{~g})$ were randomly divided into 5 groups ( $n=8$ in each group): the sham-operated group, the ICH-induced brain injury group, the ICH-induced brain injury and $1 \mu \mathrm{g} / \mathrm{kg}$ dexmedetomidine-treated group, the ICH-induced brain injury and $5 \mu \mathrm{g} / \mathrm{kg}$ dexmedetomidine-treated group, and the ICH-induced brain injury and $10 \mu \mathrm{g} / \mathrm{kg}$ dexmedetomidine-treated group. In addition, the effects of dexmedetomidine on normal rats were also evaluated.

Dexmedetomidine was procured from Hospira Inc. (Rocky Mount, NC, USA). The animals in the dexmedetomidine-treated groups received the dose of dexmedetomidine in $0.5 \mathrm{ml}$ saline intraperitoneally (i.p.) once a day for 14 consecutive days, commencing 1 day after the induction of ICH. The animals in the sham-operated group and the $\mathrm{ICH}$-induced brain injury group received an equivalent dose of saline i.p. once a day for the same duration.

Induction of collagenase-induced ICH. To induce ICH, the rats were anesthetized with Zoletil $50^{\circledR}(10 \mathrm{mg} / \mathrm{kg}$, i.p.; Vibac Laboratories, Carros, France) and placed in a stereotaxic frame. The needle of a 10- $\mu 1$ Hamilton syringe (Micro 701; Hamilton Co., Reno, NV, USA) was inserted through a burr hole into the right hippocampus to the following coordinates: $2.2 \mathrm{~mm}$ anterior and $2.2 \mathrm{~mm}$ lateral to the bregma, with a depth of $4.2 \mathrm{~mm}$. Distilled water $(1 \mu \mathrm{l})$ containing $0.2 \mathrm{U}$ collagenase (Type 4; Sigma Chemical Co., St. Louis, MO, USA) was infused over $1 \mathrm{~min}$. The needle remained in place for an additional $3 \mathrm{~min}$ following the infusion, and then was withdrawn slowly.

Step-down avoidance test. The latency in the step-down avoidance test was measured to evaluate short-term memory, as previously described (25). The rats were trained in the step-down avoidance test 14 days after the initiation of dexmedetomidine treatment. The rat was placed on a $7 \times 25 \mathrm{~cm}$ platform that was $2.5 \mathrm{~cm}$ high. The platform faced a $45 \times 25 \mathrm{~cm}$ grid of parallel stainless steel bars, $0.1 \mathrm{~cm}$ in caliber, spaced $1 \mathrm{~cm}$ apart. In the training session, the animal received a $0.2 \mathrm{~mA}$ scrambled foot shock for $2 \mathrm{sec}$ immediately upon stepping down. Two hours after the training session, the latency (sec) in each group was measured. The time the rat spent on the platform before stepping down and placing all 4 paws on the grid was defined as the latency period. Latency over $180 \mathrm{sec}$ was counted as $180 \mathrm{sec}$.

Radial 8-arm maze test. Spatial learning memory was tested using a radial 8-arm maze test, as previously described (26). The radial-arm maze apparatus consisted of a central octagonal plate $(30 \mathrm{~cm}$ in diameter) and 8 radiating arms $(50 \mathrm{~cm}$ in length and $10 \mathrm{~cm}$ in width). The apparatus was placed $1 \mathrm{~m}$ above the floor. A small receptacle filled with water $(3 \mathrm{~cm}$ in diameter and $1 \mathrm{~cm}$ in depth) was located at the end of the arms. The rat was trained 3 times before the spatial learning test. During the training sessions, the rat was deprived of water for $24 \mathrm{~h}$ and allowed to explore the water for $5 \mathrm{~min}$ after finishing each session. The test was conducted on the 13th day after the initiation of dexmedetomidine treatment. The time the rat spent seeking water at the end of the arms was counted. The test was terminated when a rat found the water in all 8 arms or when $>8$ min elapsed. The number of correct choices made before the first wrong choice was counted, and re-entry into previously visited arms was counted as the number of wrong choices made. 
Preparation of tissues. The animals were sacrificed immediately after determining the latency in the step-down avoidance test. The rats were anesthetized using Zoletil $50^{\circledR}(10 \mathrm{mg} / \mathrm{kg}$, i.p.; Vibac Laboratories), transcardially perfused with $50 \mathrm{mM}$ phosphate-buffered saline (PBS), and fixed with a freshly prepared solution consisting of $4 \%$ paraformaldehyde in $100 \mathrm{mM}$ phosphate buffer (PB, pH 7.4). The brains were dissected and stored overnight in the same fixative solution. They were then transferred to a $30 \%$ sucrose solution for cryoprotection. For immunohistochemistry, the slices were coronal sectioned (40 $\mu \mathrm{m}$ thick) using a cryostat (Leica, Nussloch, Germany). Ten slice sections on average in the CA1 region were collected from each rat. The sections of 2.5 to $2.7 \mathrm{~mm}$ posterior to the bregma were used for TUNEL staining and caspase-3 immunohistochemistry.

TUNEL staining. To visualize DNA fragmentation, a marker of apoptosis, TUNEL staining was performed using an In Situ Cell Death Detection kit ${ }^{\circledR}$ (Roche, Mannheim, Germany), according to the manufacturer's instructions (25). The sections were post-fixed in ethanol-acetic acid (2:1) and rinsed. The sections were then incubated with proteinase $\mathrm{K}(100 \mu \mathrm{g} / \mathrm{ml})$, rinsed and incubated in $3 \% \mathrm{H}_{2} \mathrm{O}_{2}$, permeabilized with $0.5 \%$ Triton X-100, rinsed again, and incubated in the TUNEL reaction mixture. The sections were rinsed and visualized using a converter-POD with $0.03 \%$ 3,3'-diaminobenzidine (DAB). Mayer's hematoxylin (Dako, Glostrup, Denmark) was used as the counterstain, and the sections were mounted onto gelatin-coated slides. The slides were air-dried overnight at room temperature and dehydrated through a gradient of ethanol and covered with coverslips using Permount ${ }^{\circledR}$ (Fisher Scientific, New Jersey, NJ, USA).

Immunohistochemistry for caspase-3. To measure caspase-3 expression, caspase-3 immunohistochemistry was performed, as previously described (25). The sections from each brain were incubated overnight with mouse anti-caspase-3 antibody (1:500; Santa Cruz Biotechnology, Santa Cruz, CA, USA), and then with biotinylated mouse secondary antibody (1:200; Vector Laboratories, Burlingame, CA, USA), and were then amplified for $1 \mathrm{~h}$ using the Vector Elite ABC kit ${ }^{\circledR}(1: 100$; Vector Laboratories). Antibody-biotin-avidin-peroxidase complexes were visualized using $0.03 \%$ DAB, and the sections were mounted onto gelatin-coated slides. The slides were air-dried overnight at room temperature and dehydrated through a gradient of ethanol and covered with coverslips using Permount ${ }^{\circledR}$ (Fisher Scientific).

Western blot analysis. Western blot analysis was performed as previously described (26). The hippocampal tissues were dissected and collected, and were then immediately frozen at $-70^{\circ} \mathrm{C}$. The right hemisphere was homogenized on ice, and lysed in lysis buffer containing $50 \mathrm{mM}$ HEPES (pH 7.5), $150 \mathrm{mM} \mathrm{NaCl}, 10 \%$ glycerol, $1 \%$ Triton X-100, $1 \mathrm{mM}$ PMSF, $1 \mathrm{mM}$ EGTA, $1.5 \mathrm{mM} \mathrm{MgCl} \mathrm{Mg}_{2} \cdot 6 \mathrm{H}_{2} \mathrm{O}, 1 \mathrm{mM}$ sodium orthovanadate and $100 \mathrm{mM}$ sodium fluoride. Protein content was measured using a Bio-Rad colorimetric protein assay kit (Hercules, CA, USA). Protein samples (30 $\mu \mathrm{g})$ were separated on a sodium dodecyl sulfate-polyacrylamide gel and transferred onto nitrocellulose membranes.
The membranes were incubated with $5 \%$ skim milk in Tris-buffered saline containing $0.1 \%$ Tween-20 and then incubated overnight at $4^{\circ} \mathrm{C}$ with the following primary antibodies: mouse anti- $\beta$-actin, anti-Bcl-2, anti-Bax, anti-caspase-3, and rabbit anti-Bid, anti-BDNF and anti-TrkB (1:1,000; Santa Cruz Biotechnology). Subsequently, the membranes were incubated for $1 \mathrm{~h}$ with secondary antibodies (1:2,000; Vector Laboratories), and band detection was performed using the enhanced chemiluminescence (ECL) detection kit (Santa Cruz Biotechnology).

Data analysis. For the confirmation of the expression of apoptotic proteins, the detected bands were calculated densitometrically using Molecular Analyst ${ }^{\mathrm{TM}}$, version 1.4.1 (Bio-Rad). The numbers of TUNEL-positive and caspase-3-positive cells in the hippocampal CA1 region were counted hemilaterally under a light microscope (Olympus, Tokyo, Japan), and they were expressed as the numbers of cells $/ \mathrm{mm}^{2}$ of the CA1 area. The area of the CA1 region was measured using the Image-Pro Plus image analysis system (Media Cyberbetics Inc., Silver Spring, MD, USA).

Statistical analysis was performed using one-way ANOVA followed by Duncan's post-hoc test, and the results are expressed as the means \pm standard error of the mean (SEM). A P-value $<0.05$ was considered to indicate a statistically signficant difference.

\section{Results}

Effect of dexmedetomidine on short-term memory in the step-down avoidance test. The latency of the reactions of the rats in the step-down avoidance test is presented in Fig. 1 (left panel). The latency was decreased following the induction of ICH $(\mathrm{P}<0.05)$ and treatment with dexmedetomidine increased the latency in the rats with ICH-induced brain injury $(\mathrm{P}<0.05)$. The present results revealed that dexmedetomidine alleviated ICH-induced short-term memory impairment. In the normal rats, dexmedetomidine exerted no significant effect on latency (Fig. 2, left panel).

Effect of dexmedetomidine on spatial learning memory in the radial 8-arm maze test. The time taken to successfully perform the task, the number of correct choices made before the first wrong choice, and the number of wrong choices made before the 8 successful performances in the radial 8-arm maze test are presented in Fig. 1 (right panel). The time taken to successfully perform the task was longer, the number of correct choices made was lower, and the number of wrong choices made was higher in the rats with $\mathrm{ICH}$-induced brain injury compared to the control rats $(\mathrm{P}<0.05)$. Treatment with dexmedetomidine reduced the time taken to successfully perform the task, increased the number of correct choices made, and decreased the number of wrong choices made in the rats with $\mathrm{ICH}$-induced brain injury $(\mathrm{P}<0.05)$. The present results revealed that treatment with dexmedetomidine alleviated the ICH-induced spatial learning memory impairment. In the normal rats, dexmedetomidine exerted no significant effect on the time taken to successfully perform the task, the number of correct choices made, and the number of wrong choices made (Fig. 2, right panel). 

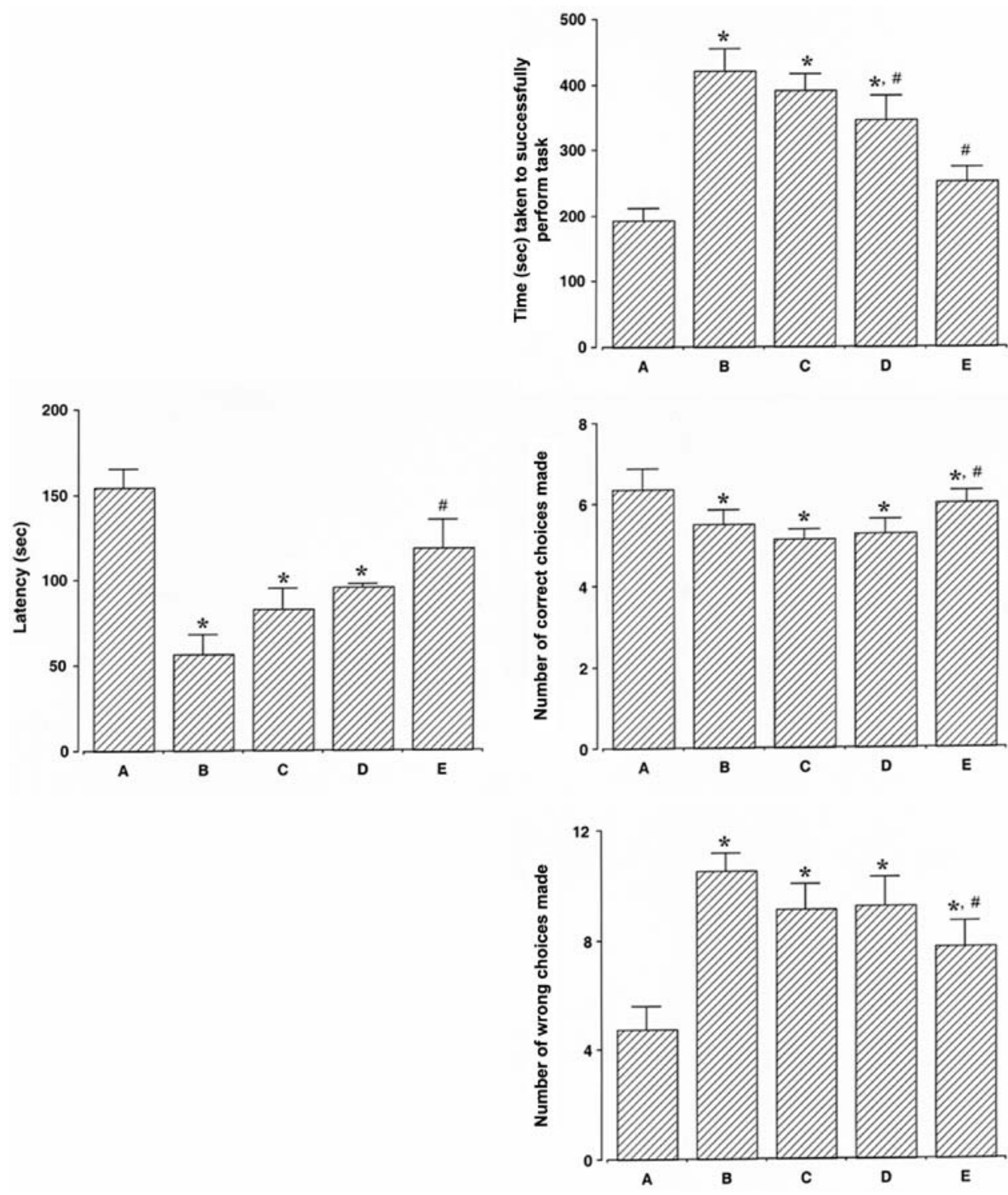

Figure 1. Effects of dexmedetomidine on short-term and spatial learning memory in rats with intracerebral hemorrhage (ICH)-induced brain injury. Left panel, step-down avoidance test; right panel, radial 8-arm maze test. (A) Sham-operated group, (B) ICH-induced brain injury group, (C) ICH-induced brain injury and $1 \mu \mathrm{g} / \mathrm{kg}$ dexmedetomidine-treated group, (D) ICH-induced brain injury and $5 \mu \mathrm{g} / \mathrm{kg}$ dexmedetomidine-treated group, (E) ICH-induced brain injury and $10 \mu \mathrm{g} / \mathrm{kg}$ dexmedetomidine-treated group. The results are presented as the means \pm standard error of the mean (SEM). "P<0.05 compared to the sham-operated group; ${ }^{\text {"}} \mathrm{P}<0.05$ compared to the ICH-induced brain injury group.

Effect of dexmedetomidine on the number of TUNEL-positive cells in the hippocampal CAl region. Photomicrographs of TUNEL-positive cells in the hippocampal CA1 region are presented in Fig. 3 (upper panel). The induction of ICH increased DNA fragmentation in the CA1 region $(\mathrm{P}<0.05)$ and treatment with dexmedetomidine suppressed the $\mathrm{ICH}$-induced DNA fragmentation $(\mathrm{P}<0.05)$. In the normal rats, dexmedetomidine exerted no significant effect on DNA fragmentation (Fig. 4, upper panel).

Effect of dexmedetomidine on caspase-3 expression in the CAl region. Photomicrographs of caspase-3-positive cells in the hippocampal CA1 region are presented in Fig. 3 (lower panel). The induction of ICH increased caspase- 3 expression in the $\mathrm{CA1}$ region $(\mathrm{P}<0.05)$ and treatment with dexmedetomidine suppressed the ICH-induced caspase- 3 expression $(\mathrm{P}<0.05)$. In the normal rats, dexmedetomidine exerted no significant effect on caspase-3 expression (Fig. 4, lower panel).

Effect of dexmedetomidine on the protein levels of Bcl-2 and Bax in the hippocampus. To determine the expression of the anti-apoptotic factor, Bcl-2, we evaluated the expression level of Bcl-2 (26-29 kDa) by western blot analysis (Fig. 5, upper left panel). The induction of ICH suppressed Bcl-2 expression in the hippocampus $(\mathrm{P}<0.05)$ and treatment with dexmedetomidine increased $\mathrm{Bcl}-2$ expression in the rats with $\mathrm{ICH}-$ induced brain injury $(\mathrm{P}<0.05)$. In the normal rats, dexmedetomidine exerted no significant effect on Bcl-2 expression (Fig. 6, upper left panel).

To determine the expression of the pro-apoptotic factor, Bax, we evaluated the expression level of Bax (24 kDa) by western blot analysis (Fig. 5, middle left panel). The induc- 

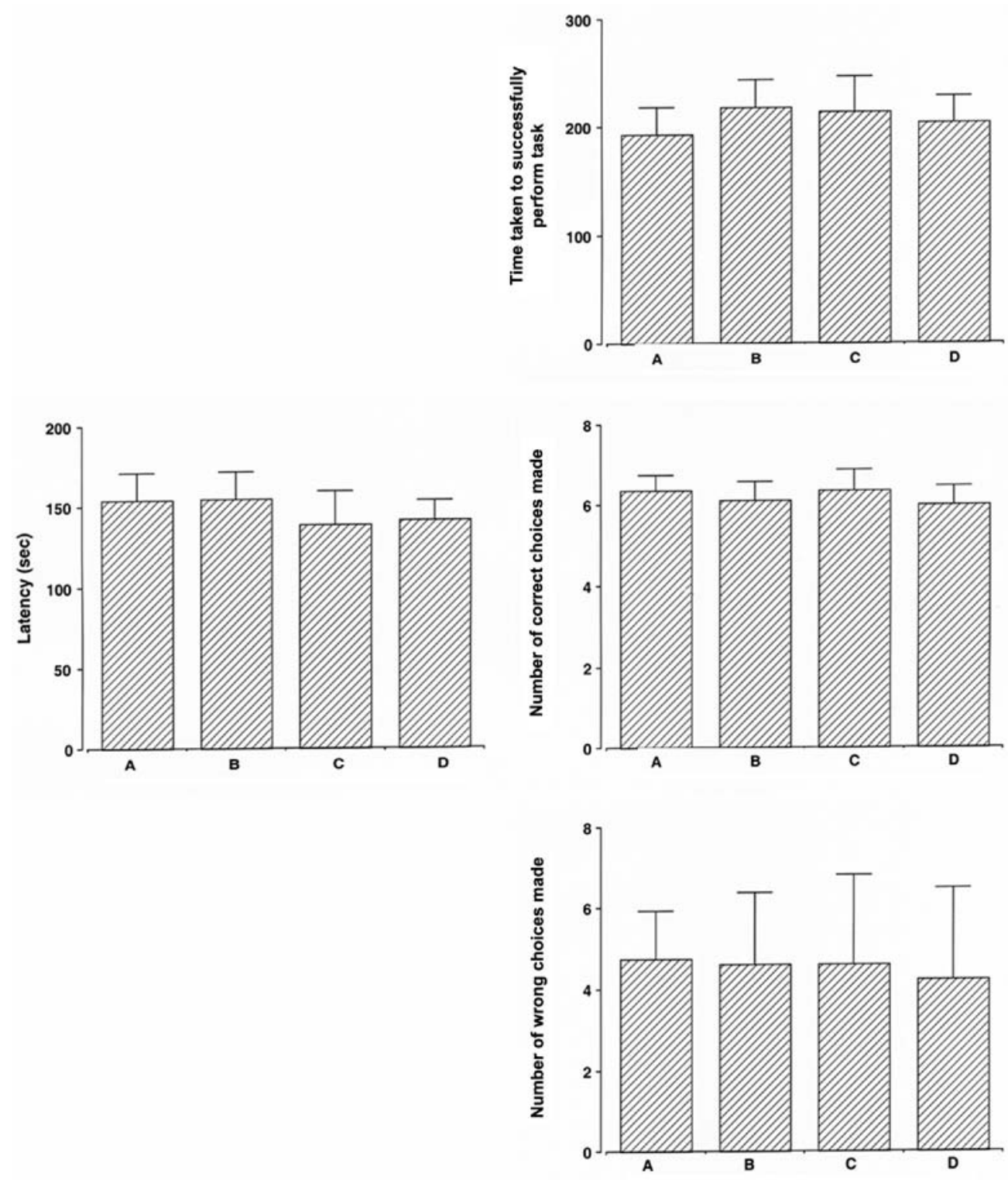

Figure 2. Effects of dexmedetomidine on short-term and spatial learning memory in normal rats. Left panel, step-down avoidance test; right panel, radial 8-arm maze test. (A) Sham-operated group, (B) sham-operated and $1 \mu \mathrm{g} / \mathrm{kg}$ dexmedetomidine-treated group, (C) sham-operated and $5 \mu \mathrm{g} / \mathrm{kg}$ dexmedetomidine-treated group, (D) sham-operated and $10 \mu \mathrm{g} / \mathrm{kg}$ dexmedetomidine-treated group. The results are presented as the means \pm standard error of the mean (SEM).

tion of ICH increased Bax expression in the hippocampus $(\mathrm{P}<0.05)$ and treatment with dexmedetomidine inhibited the ICH-induced Bax expression $(\mathrm{P}<0.05)$. In the normal rats, dexmedetomidine exerted no significant effect on Bax expression (Fig. 6, middle left panel).

Furthermore, we analyzed the ratio of Bax to Bcl-2 (Fig. 5, lower left panel). The induction of ICH enhanced the ratio of $\mathrm{Bax}$ to $\mathrm{Bcl}-2$ in the hippocampus $(\mathrm{P}<0.05)$ and treatment with dexmedetomidine suppressed the ratio of Bax to $\mathrm{Bcl}-2$ in the rats with ICH-induced brain injury $(\mathrm{P}<0.05)$. In the normal rats, dexmedetomidine exerted no significant effect on the Bax to Bcl-2 ratio (Fig. 6, lower left panel).

Effect of dexmedetomidine on the protein expression level of Bid in the hippocampus. To determine the expression of another pro-apoptotic factor, Bid, we examined the expression level of Bid (22 kDa) by western blot analysis (Fig. 5, upper middle panel). The induction of ICH increased Bid expression in the hippocampus $(\mathrm{P}<0.05)$ and treatment with dexmedetomidine suppressed the ICH-induced Bid expression in the rats with $\mathrm{ICH}$-induced brain injury $(\mathrm{P}<0.05)$. In the normal rats, dexmedetomidine exerted no significant effect on Bid expression (Fig. 6, upper middle panel).

Effect of dexmedetomidine on the protein expression level of caspase- 3 in the hippocampus. To determine the expression of the apoptosis executioner, caspase-3, we evaluated the protein expression level of caspase-3 (17 kDa) by western blot analysis (Fig. 5, lower middle panel). The induction of ICH increased caspase-3 expression in the hippocampus $(\mathrm{P}<0.05)$ and treatment with dexmedetomidine suppressed the ICH-induced caspase 3 expression $(\mathrm{P}<0.05)$. In the normal rats, dexmedetomidine exerted no significant effect on caspase 3 expression (Fig. 6, lower middle panel). 

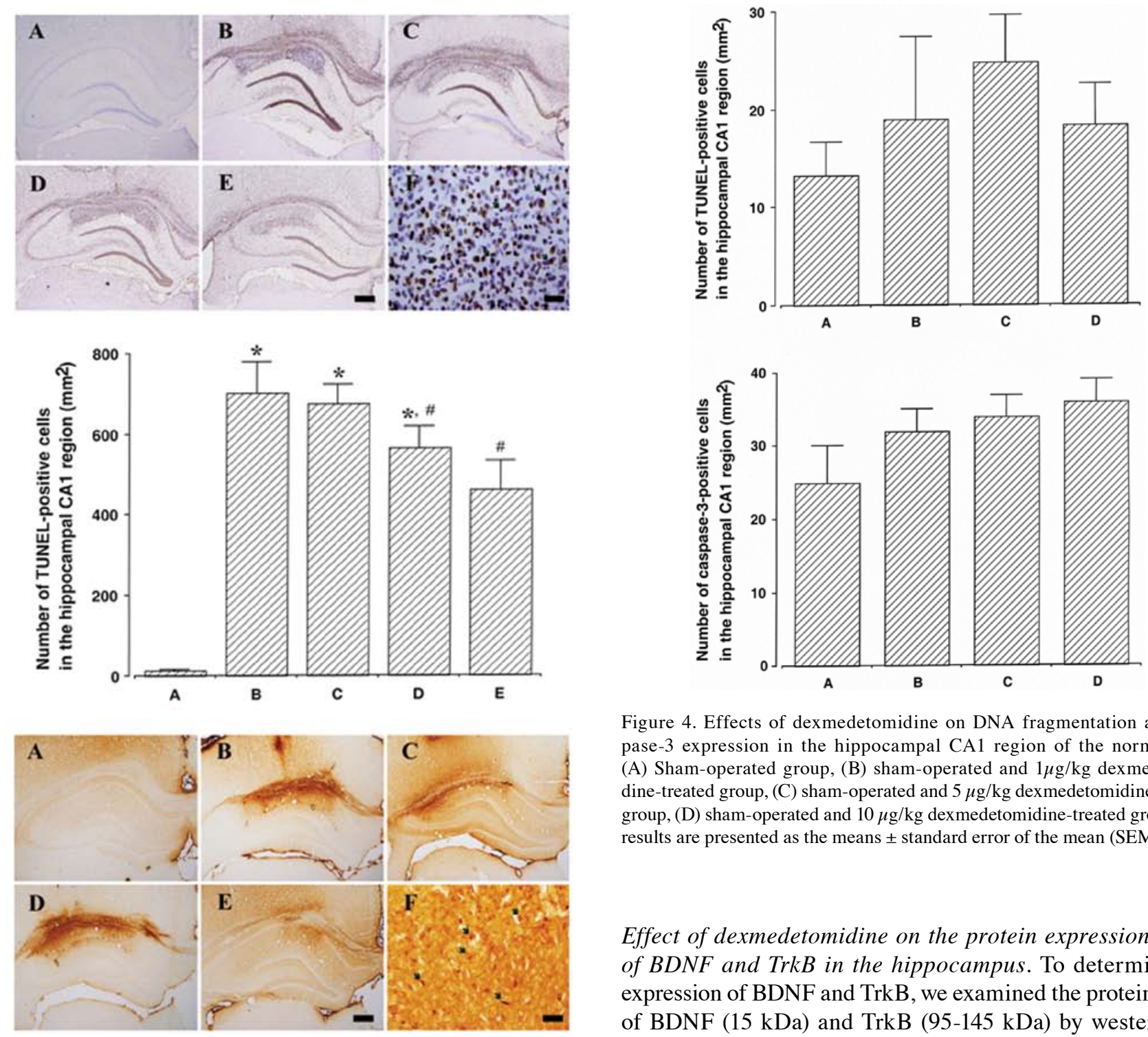

Figure 4. Effects of dexmedetomidine on DNA fragmentation and caspase-3 expression in the hippocampal CA1 region of the normal rats. (A) Sham-operated group, (B) sham-operated and $1 \mu \mathrm{g} / \mathrm{kg}$ dexmedetomidine-treated group, (C) sham-operated and $5 \mu \mathrm{g} / \mathrm{kg}$ dexmedetomidine-treated group, (D) sham-operated and $10 \mu \mathrm{g} / \mathrm{kg}$ dexmedetomidine-treated group. The results are presented as the means \pm standard error of the mean (SEM).

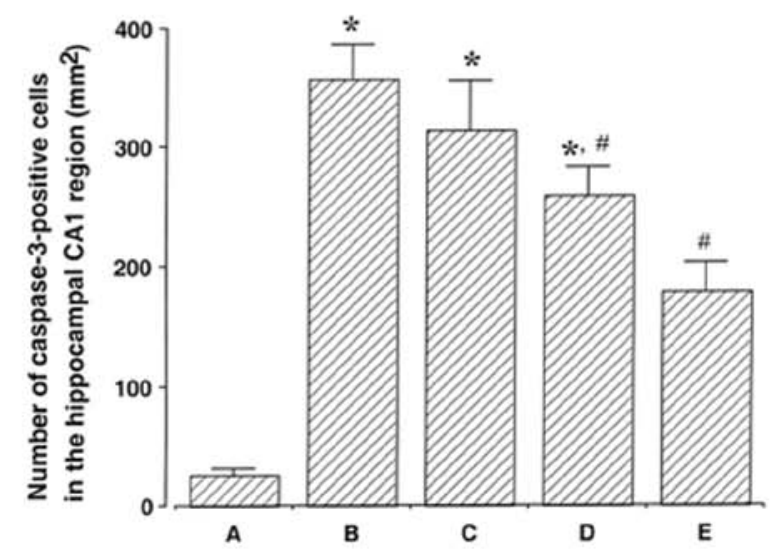

Figure 3. Effects of dexmedetomidine on DNA fragmentation and caspase-3 expression in the hippocampal CA1 region of the rats with intracerebral hemorrhage (ICH)-induced brain injury. Upper panels, terminal deoxynucleotidyl transferase-mediated dUTP nick end-labeling (TUNEL)-positive cells; lower panels, caspase-3-positive cells. (A-E) The scale bar represents $400 \mu \mathrm{m}$ and (F) $100 \mu \mathrm{m}$. (A) Sham-operated group, (B) ICH-induced brain injury group, (C) ICH-induced brain injury and $1 \mu \mathrm{g} / \mathrm{kg}$ dexmedetomidine-treated group, (D) ICH-induced brain injury and $5 \mu \mathrm{g} / \mathrm{kg}$ dexmedetomidine-treated group, (E) ICH-induced brain injury and $10 \mu \mathrm{g} / \mathrm{kg}$ dexmedetomidine-treated group. The results are presented as the means \pm standard error of the mean (SEM). ${ }^{*} \mathrm{P}<0.05$ compared to the sham-operated group. ${ }^{*} \mathrm{P}<0.05$ compared to the $\mathrm{ICH}$-induced brain injury group.

Effect of dexmedetomidine on the protein expression levels of BDNF and TrkB in the hippocampus. To determine the expression of BDNF and TrkB, we examined the protein levels of BDNF (15 kDa) and TrkB (95-145 kDa) by western blot analysis (Fig. 5, right panel). The induction of ICH decreased BDNF and TrkB expression in the hippocampus $(\mathrm{P}<0.05)$ and treatment with dexmedetomidine enhanced BDNF and TrkB expression in the rats with ICH-induced brain injury $(\mathrm{P}<0.05)$. In the normal rats, dexmedetomidine exerted no significant effect on BDNF and TrkB expression (Fig. 6, right panel).

\section{Discussion}

The animal model of ICH, induced by an injection of collagenase, has been used to study the mechanisms of brain injuries. The intracerebral injection of collagenase into the hippocampus induces a lesion with triggered apoptotic neuronal cell death in the hippocampus $(2,3)$. Cognitive impairment is a common symptom following ICH, with executive and perceptual disorders being the most frequent (27). Widespread patterns of cognitive deficits have been observed in ICH patients (28).

In the present study, a step-down avoidance test showed decreased latency in the rats with ICH-induced brain injury, indicating the ICH-induced deterioration of short-term memory. Treatment with dexmedetomidine increased the latency in the rats with ICH-induced brain injury, indicating that dexmedetomidine alleviated ICH-induced short-term memory impairment (Fig. 1, left panel). A radial-arm maze 

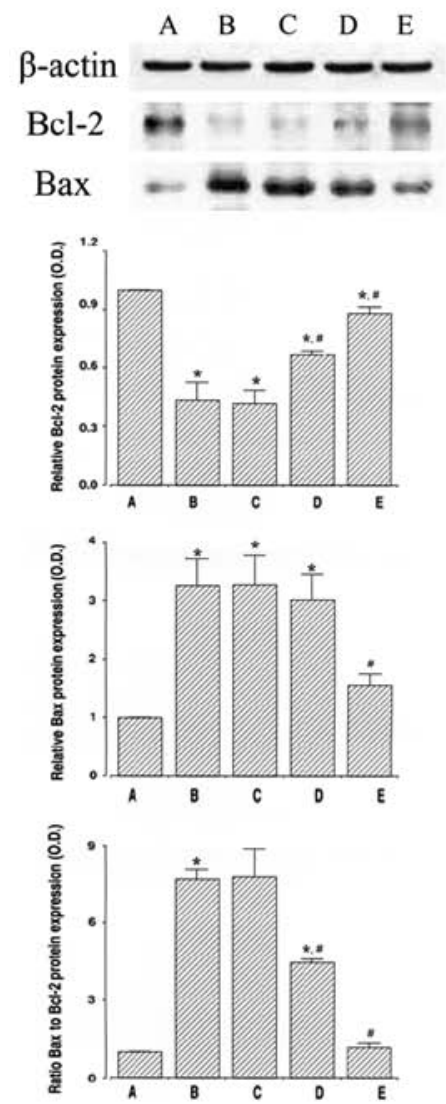

A $\quad$ B $\quad$ C $\quad$ D $\quad$ E
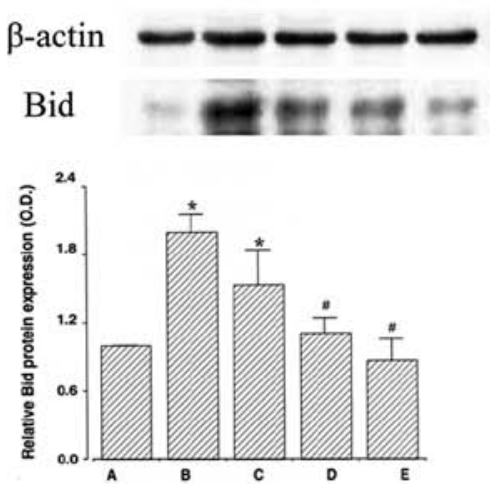

A $\quad$ B $\quad$ C $\quad$ D $\quad$ E
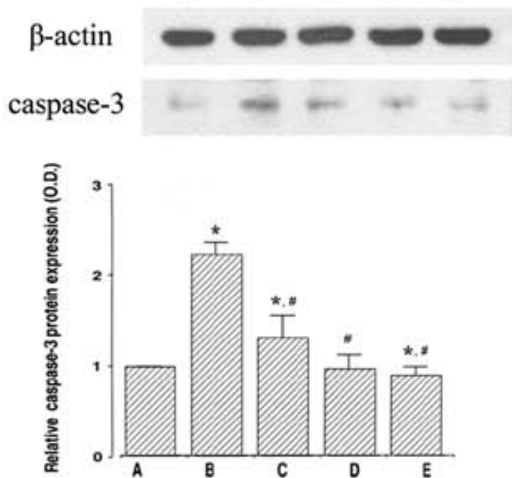

A $\quad$ B $\quad$ C $\quad$ D $\quad$ E
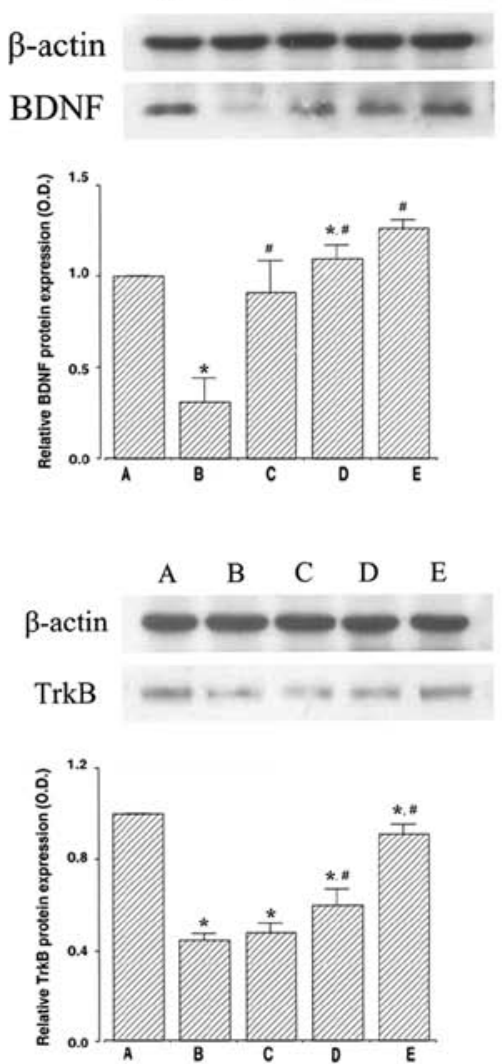

Figure 5. Effects of dexmedetomidine on the expression of apoptosis-related proteins and neurotrophic factors in the hippocampus of the rats with intracerebral hemorrhage (ICH)-induced brain injury. $\beta$-actin was used as the internal control (46 kDa). Left panel, Bcl-2 and Bax proteins; middle panel, Bid and caspase-3 proteins; right panel, brain-derived neurotrophic factor (BDNF) and tyrosine kinase B (TrkB) proteins. (A) Sham-operated group, (B) ICH-induced brain injury group, (C) ICH-induced brain injury and $1 \mu \mathrm{g} / \mathrm{kg}$ dexmedetomidine-treated group, (D) ICH-induced brain injury and $5 \mu \mathrm{g} / \mathrm{kg}$ dexmedetomidine-treated group, (E) ICH-induced brain injury and $10 \mu \mathrm{g} / \mathrm{kg}$ dexmedetomidine-treated group. The results are presented as the means \pm standard error of the mean (SEM). ${ }^{\text {" }} \mathrm{P}<0.05$ compared to the sham-operated group; ${ }^{*} \mathrm{P}<0.05$ compared to the ICH-induced brain injury group.

test also showed a longer time taken to successfully perform the task, a lower number of correct choices made, and a higher number of wrong choices made in the rats with $\mathrm{ICH}$-induced brain injury, indicating the $\mathrm{ICH}$-induced deterioration of spatial learning memory. Treatment with dexmedetomidine shortened the time taken to successfully perform the task, increased the number of correct choices made, and decreased the number of wrong choices made in the rats with $\mathrm{ICH}$-induced brain injury, demonstrating that dexmedetomidine alleviated the ICH-induced impairment of spatial learning memory (Fig. 1, right panel).

Hypoxic ischemia injury has been shown to induce short-term memory deterioration in a step-down avoidance test, as well as the impairment of spatial learning memory in a radial 8-arm maze test (29). In a previous study, maternal separation induced a decrease in latency in a step-down avoidance test, representing memory loss. By contrast, the increase in latency (to what are considered normal levels) indicated the alleviation of memory loss (30).

In this study, the numbers of TUNEL-positive and caspase-3-positive cells were increased following the induction of ICH. By contrast, treatment with dexmedetomidine decreased the numbers of TUNEL-positive and caspase-3-positive cells in the rats with ICH-induced brain injury (Fig. 3). In addition, the expression of Bid and caspase-3 increased following the induction of ICH. By contrast, treatment with dexmedetomidine suppressed the expression of Bid and caspase- 3 in the rats with $\mathrm{ICH}$-induced brain injury (Fig. 5, middle panel). Our results demonstrated that dexmedetomidine treatment alleviated $\mathrm{ICH}$-induced apoptosis in the hippocampus.

Apoptosis appears to play a key role in neuronal cell death during stroke $(31,32)$. The induction of ICH in rats has been shown to induce neuronal cell death, and apoptosis has been closely implicated in ICH-induced neuronal cell death $(7,31)$. The upregulation of caspase- 3 is an important hallmark of apoptosis following ischemic and hemorrhagic brain insults $(3,33)$. An increase in the numbers of TUNEL-positive and caspase-3-positive cells in the hippocampus indicates an enhancement of apoptotic neuronal cell death in the hippocampus $(3,30)$. The pro-apoptotic molecule, Bid, contributes to the demise of nerve cells following cerebral ischemia by the release of cytochrome $c$ and activation of caspases (34). Bid expression in the hippocampus has also been shown to be upregulated following transient global cerebral ischemia in rats (35).

In our study, the expression of Bcl-2 was downregulated and that of Bax was upregulated in the hippocampus following the induction of $\mathrm{ICH}$, resulting in an increase in the ratio of Bax to Bcl-2. Treatment with dexmedetomidine enhanced $\mathrm{Bcl}-2$ expression and suppressed Bax expression in the rats 

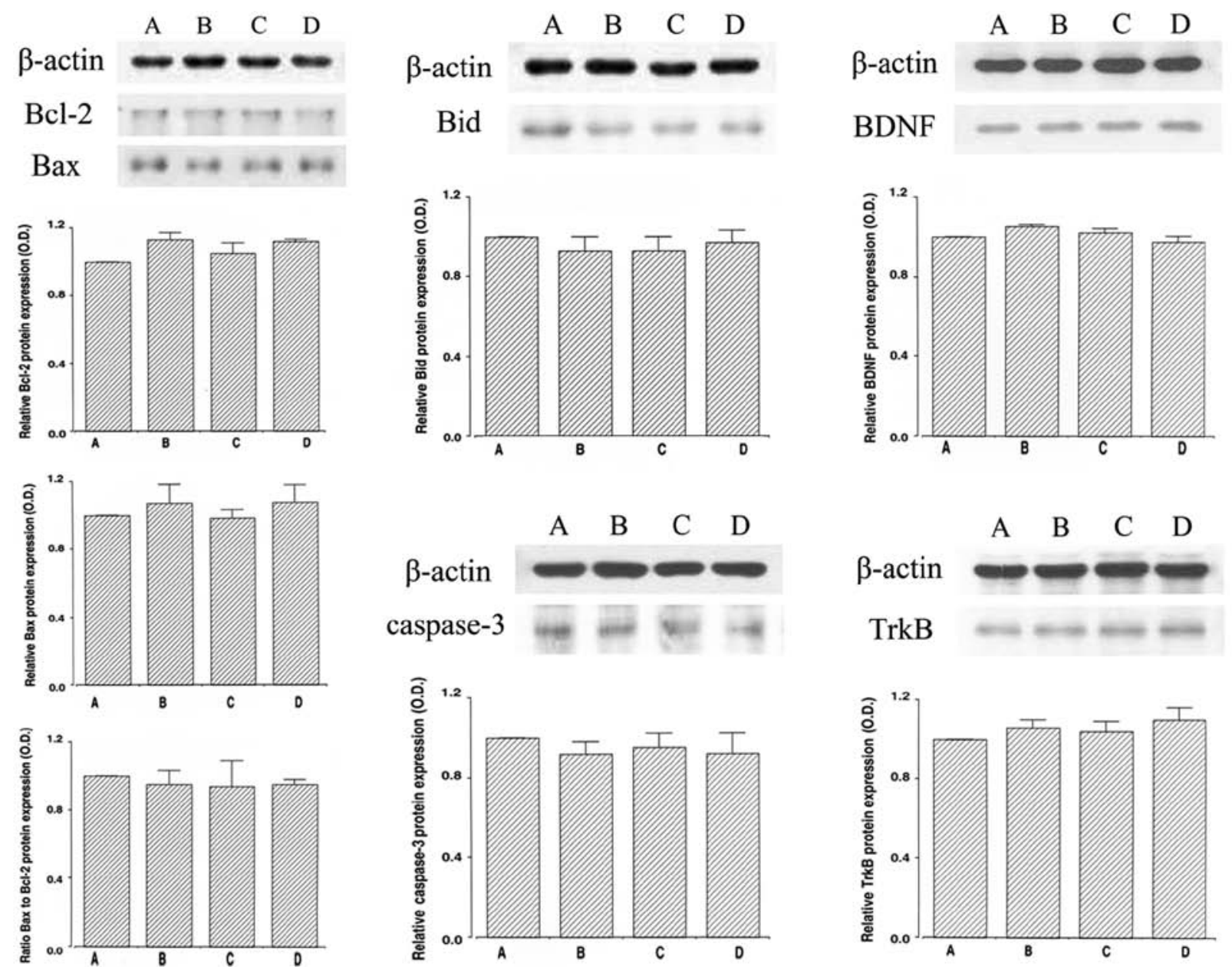

Figure 6. Effects of dexmedetomidine on the expression of apoptosis-related proteins and neurotrophic factors in the hippocampus of the normal rats. $\beta$-actin was used as the internal control (46 kDa). Left panel, Bcl-2 and Bax proteins; middle panel, Bid and caspase-3 proteins; right panel, brain-derived neurotrophic factor (BDNF) and tyrosine kinase B (TrkB) proteins. (A) Sham-operated group, (B) sham-operated and $1 \mu \mathrm{g} / \mathrm{kg}$ dexmedetomidine-treated group, (C) shamoperated and $5 \mu \mathrm{g} / \mathrm{kg}$ dexmedetomidine-treated group, (D) sham-operated and $10 \mu \mathrm{g} / \mathrm{kg}$ dexmedetomidine-treated group. The results are presented as the means \pm standard error of the mean (SEM).

with ICH-induced brain injury, resulting in a decrease in the ratio of Bax to Bcl-2 (Fig. 5, left panel). Our results demonstrated that dexmedetomidine exerted its anti-apoptotic effects through the upregulation of Bcl-2 and the downregulation of Bax expression in the hippocampus of rats with IHC-induced brain injury.

The Bcl-2 family proteins have one or more Bcl-2 homology domains and play a crucial role in intracellular apoptotic signal transduction by regulating the permeability of the mitochondrial membrane. Bax, Bcl-xL, Bak, Bid and Bad are pro-apoptotic, and they eliminate the mitochondrial membrane potential by affecting the permeability transition pore and facilitating the release of cytochrome $c$. Conversely, Bcl-2 and Bcl-xL function to conserve the membrane potential and block the release of cytochrome $c$ (36). Bcl-2 and Bcl-xL form heterodimers with the main pro-apoptotic member, Bax, and they are thus incapacitated from their protective function (37). Thus, the balance of $\mathrm{Bax} / \mathrm{Bcl}-2$ is one of the crucial factors determining whether the cells undergo apoptosis (8). In the study of Engelhard et al (38), dexmedetomidine upregulated $\mathrm{Bcl}-2$ expression, and they suggested that the neuroprotective property of dexmedetomidine involves the modulation of the balance between pro- and anti-apoptotic proteins. Blockade of $\alpha_{2}$-adrenoreceptors has been shown to decrease the Bax mRNA level and increase the Bcl-xL mRNA level in the cortex and hippocampus, indicating anti-apoptotic effects (39). Dexmedetomidine has also been shown to inhibit isoflurane-induced cortical apoptosis, and this protective effect of dexmedetomidine was achieved by the reversal of the isoflurane-induced decrease in Bcl-2 expression (40).

In this study, the expression of BDNF and TrkB was suppressed in the hippocampus following the inductionv of ICH. By contrast, dexmedetomidine treatment increased BDNF and TrkB expression in the rats with $\mathrm{ICH}$-induced brain injury (Fig. 5, right panel). The results from the present study indicate that the reduced BDNF and TrkB expression in the hippocampus is involved in the short-term and spatial learning memory impairment induced by $\mathrm{ICH}$. The increase in BDNF and TrkB expression following treatment with dexmedetomidine ameliorated the ICH-induced memory deficits.

BDNF is involved in neuronal survival and differentiation, and plays an important role in the learning process due 
to its involvement in long-term potentiation in the hippocampus $(9,10,41)$. Plasminogen activator (tPA), by activating the extracellular protease plasmin, converts the precursor proBDNF to the mature BDNF and mature BDNF is a key protein for long-term potentiation (42). BDNF expression in the hippocampus has been shown to be suppressed following traumatic brain injury and hemorrhage hypotension, suggesting that BDNF exerts neuroprotective effects $(30,43)$. The enhanced BDNF expression in the hippocampus improves both short-term and long-term memory, and contributes to neuronal survival and differentiation $(44,45)$. The age-induced loss of short-term and spatial working memory is accompanied with the suppression of BDNF expression in the hippocampus, while the increased BDNF expression contributes to memory enhancement (26). BDNF with fibrin-binding domain significantly reduce the hematoma volume, alleviate tissue loss, promote neuronal cell regeneration and improve behavioral performance in rats with ICH-induced brain injury (46).

As mentioned above, the anti-apoptotic and neuroprotective effects of dexmedetomidine against various brain insults have been well documented. However, sedative-hypnotic drugs are known to impair memory function; however, the details regarding the nature of these effects are unknown. The memory-deteriorating effects of dexmedetomidine have also been reported (22-24).

In the present study, we focused on the memory-enhancing effects of dexmedetomidine under ICH conditions. The present results showed that dexmedetomidine ameliorated ICH-induced memory impairment. Dexmedetomidine also exerted anti-apoptotic effects and increased BDNF expression in the hippocampus of rats with ICH-induced brain injury. In the normal rats, dexmedetomidine exerted no significant effects on apoptosis and memory function, indicating that dexmedetomidine exerts no detrimental effects on normal rats (Figs. 2, 4 and 6). Based on the present results, dexmedetomidine may be used as a therapeutic agent for the conservation of memory function in stroke patients.

\section{Acknowledgements}

This study was supported by the Basic Science Research Program through the National Research Foundation of Korea funded by the Ministry of Education, Science and Technology of Korea (2011-0013878).

\section{References}

1. Ferro JM: Update on intracerebral haemorrhage. J Neurol 253 985-999, 2006.

2. Lee HH, Kim H, Lee MH, Chang HK, Lee TH, Jang MH, Shin MC, Lim BV, Shin MS, Kim YP, Yoon JH, Jeong IG and Kim CJ: Treadmill exercise decreases intrastriatal hemorrhageinduced neuronal cell death via suppression on caspase-3 expression in rats. Neurosci Lett 352: 33-36, 2003.

3. Suh HJ, So SM, Na YG, Ko IG, Kim SE, Sung YS, Shin MS, Kim CJ, Cho YS and Kim KH: Neuroprotective effects of tamsulosin on intracerebral hemorrhage. Neural Regen Res 6: 2505-2510, 2011

4. Thompson CB: Apoptosis in the pathogenesis and treatment of disease. Science 267: 1456-1462, 1995.

5. Johnson EM Jr, Greenlund LJ, Atkins PT and Hsu CY: Neuronal apoptosis: current understanding of molecular mechanisms and potential role in ischemic brain injury. J Neurotrauma 12: 843-852, 1995
6. Reed CJ: Apoptosis and cancer: strategies for integrating programmed cell death. Semin Hematol 37 (Suppl 7): 9-16, 2000.

7. Gong C, Boulis N, Qian J, Turner DE, Hoff JT and Keep RF: Intracerebral hemorrhage-induced neuronal death. Neurosurgery 48: 875-882, 2001.

8. Upadhyay D, Panduri V, Ghio A and Kamp DW: Particulate matter induces alveolar epithelial cell DNA damage and apoptosis: role of free radicals and the mitochondria. Am J Respir Cell Mol Biol 29: 180-187, 2003.

9. Gomez-Pinilla F and Vaynman S: A 'deficient environment' in prenatal life may compromise systems important for cognitive function by affecting BDNF in the hippocampus. Exp Neurol 192: 235-243, 2005

10. Minichiello L: TrkB signalling pathways in LTP and learning. Nat Rev Neurosci 10: 850-860, 2009.

11. Zimmerberg B, Foote HE and Van Kempen TA: Olfactory association learning and brain-derived neurotrophic factor in an animal model of early deprivation. Dev Psychobiol 51: 333-344, 2009.

12. Hasegawa Y, Suzuki H, Altay O and Zhang JH: Preservation of tropomyosin-related kinase B (TrkB) signaling by sodium orthovanadate attenuates early brain injury after subarachnoid hemorrhage in rats. Stroke 42: 477-483, 2011.

13. Ard J, Doyle W and Bekker A: Awake craniotomy with dexmedetomidine in pediatric patients. J Neurosurg Anesthesiol 15: 263-266, 2003.

14. Ramsay MA and Luterman DL: Dexmedetomidine as a total intravenous anesthetic agent. Anesthesiology 101: 787-790, 2004.

15. Dahmani S, Rouelle D, Gressens P and Mantz J: Effects of dexmedetomidine on hippocampal focal adhesion kinase tyrosine phosphorylation in physiologic and ischemic conditions. Anesthesiology 103: 969-977, 2005.

16. Laudenbach V, Mantz J, Lagercrantz H, Desmonts JM, Evrard P and Gressens P: Effects of $\alpha_{2}$-adrenoceptor agonists on perinatal excitotoxic brain injury: comparison of clonidine and dexmedetomidine. Anesthesiology 96: 134-141, 2002.

17. Ma D, Hossain M, Rajakumaraswamy N, Arshad M, Sanders RD, Franks NP and Maze M: Dexmedetomidine produces its neuroprotective effect via the $\alpha_{2 \mathrm{~A}}$-adrenoceptor subtype. Eur J Pharmacol 502: 87-97, 2004.

18. Eser O, Fidan H, Sahin O, Cosar M, Yaman M, Mollaoglu H, Songur A and Buyukbas S: The influence of dexmedetomidine on ischemic rat hippocampus. Brain Res 1218: 250-256, 2008.

19. Cosar M, Eser O, Fidan H, Sahin O, Buyukbas S, Ela Y, Yagmurca $\mathrm{M}$ and Ozen OA: The neuroprotective effect of dexmedetomidine in the hippocampus of rabbits after subarachnoid hemorrhage. Surg Neurol 71: 54-59, 2009.

20. Ayoglu H, Gul S, Hanci V, Bahadir B, Bektas S, Mungan AG, Turan IO and Acikgoz B: The effects of dex medetomidine dosage on cerebral vasospasm in a rat subarachnoid haemorrhage model. J Clin Neurosci 17: 770-773, 2010.

21. Hall JE, Uhrich TD, Barney JA, Arain SR and Ebert TJ: Sedative, amnestic, and analgesic properties of small-dose dexmedetomidine infusions. Anesth Analg 90: 699-705, 2000

22. Takamatsu I, Iwase A, Ozaki M, Kazama T, Wada K and Sekiguchi M: Dexmedetomidine reduces long-term potentiation in mouse hippocampus. Anesthesiology 108: 94-102, 2008.

23. van Oostrom H, Stienen PJ, Doornenbal A and Hellebrekers LJ: The $\alpha_{2}$-adrenoceptor agonist dexmedetomidine suppresses memory formation only at doses attenuating the perception of sensory input. Eur J Pharmacol 629: 58-62, 2010.

24. Hayama HR, Drumheller KM, Mastromonaco M, Reist C, Cahill LF and Alkire MT: Event-related functional magnetic resonance imaging of a low dose of dexmedetomidine that impairs long-term memory. Anesthesiology 117: 981-995, 2012.

25. Ko IG, Shin MS, Kim BK, Kim SE, Sung YH, Kim TS, Shin MC, Cho HJ, Kim SC, Kim SH, Kim KH, Shin DH and Kim CJ: Tadalafil improves short-term memory by suppressing ischemiainduced apoptosis of hippocampal neuronal cells in gerbils. Pharmacol Biochem Behav 91: 629-635, 2009.

26. Kim SE, Ko IG, Kim BK, Shin MS, Cho S, Kim CJ, Kim SH, Baek SS, Lee EK and Jee YS: Treadmill exercise prevents aging-induced failure of memory through an increase in neurogenesis and suppression of apoptosis in rat hippocampus. Exp Gerontol 45: 357-365, 2010.

27. Nys GM, van Zandvoort MJ, de Kort PL, Jansen BP, de Haan EH and Kappelle LJ: Cognitive disorders in acute stroke: prevalence and clinical determinants. Cerebrovasc Dis 23: 408-416, 2007.

28. Su CY, Chen HM, Kwan AL, Lin YH and Guo NW: Neuropsychological impairment after hemorrhagic stroke in basal ganglia. Arch Clin Neuropsychol 22: 465-474, 2007. 
29. Ko IG, Cho H, Kim SE, Kim JE, Sung YH, Kim BK, Shin MS, Cho S, Pak YK and Kim CJ: Hypothermia alleviates hypoxic ischemia-induced dopamine dysfunction and memory impairment in rats. Anim Cells Syst 15: 279-286, 2011.

30. Baek SS, Jun TW, Kim KJ, Shin MS, Kang SY and Kim CJ Effects of postnatal treadmill exercise on apoptotic neuronal cell death and cell proliferation of maternal-separated rat pups. Brain Dev 34: 45-56, 2012.

31. Matsushita K, Meng W, Wang X, Asahi M, Asahi K, Moskowitz MA and Lo EH: Evidence for apoptosis after intercerebral hemorrhage in rat striatum. J Cereb Blood Flow Metab 20: 396-404, 2000.

32. Qureshi AI: Nonsteroidal anti-inflammatory drugs and the risk of intracerebral hemorrhage. Stroke 34: 379-386, 2003.

33. Benchoua A, Braudeau J, Reis A, Couriaud C and Onténiente B: Activation of proinflammatory caspases by cathepsin B in focal cerebral ischemia. J Cereb Blood Flow Metab 24: 1272-1279, 2004.

34. Plesnila N, Zinkel S, Amin-Hanjani S, Qiu J, Korsmeyer SJ and Moskowitz MA: Function of BID - a molecule of the bcl-2 family - in ischemic cell death in the brain. Eur Surg Res 34: 37-41, 2002.

35. Niizuma K, Endo H, Nito C, Myer DJ, Kim GS and Chan PH: The PIDDosome mediates delayed death of hippocampal CA1 neurons after transient global cerebral ischemia in rats. Proc Nat Acad Sci USA 105: 16368-16373, 2008.

36. Sugawara T, Fujimura M, Noshita N, Kim GW, Saito A, Hayashi T Narasimhan P, Maier CM and Chan PH: Neuronal death/survival signaling pathways in cerebral ischemia. NeuroRx 1: 17-25, 2004.

37. Kuwana T and Newmeyer DD: Bcl-2-family proteins and the role of mitochondria in apoptosis. Curr Opin Cell Biol 15: 691-699, 2003.

38. Engelhard K, Werner C, Eberspächer E, Bachl M, Blobner M, Hildt E, Hutzler P and Kochs E: The effect of the $\alpha_{2}$-agonist dexmedetomidine and the N-methyl-D-aspartate antagonist $\mathrm{S}(+)$-ketamine on the expression of apoptosis-regulating proteins after incomplete cerebral ischemia and reperfusion in rats. Anesth Analg 96: 524-531, 2003.
39. Il'inykh FA, Bannova AV, Kalinina TS and Dygalo NN: Effects of ligands of $\alpha_{2}$-adrenoceptors on mRNA level of apoptotic proteins in the developing rat brain. Izv Akad Nauk Ser Biol 1: 104-109, 2008 (In Russian).

40. Sanders RD, Sun P, Patel S, Li M, Maze M and Ma D Dexmedetomidine provides cortical neuroprotection: impact on anaesthetic-induced neuroapoptosis in the rat developing brain. Acta Anaesthesiol Scand 54: 710-716, 2010.

41. Xu B, Gottschalk W, Chow A, Wilson RI, Schnell E, Zang K, Wang D, Nicoll RA, Lu B and Reichardt LF: The role of brainderived neurotrophic factor receptors in the mature hippocampus: modulation of long-term potentiation through a presynaptic mechanism involving TrkB. J Neurosci 20: 6888-6897, 2000 .

42. Pang PT, Teng HK, Zaitsev E, Woo NT, Sakata K, Zhen S, Teng KK, Yung WH, Hempstead BL and Lu B: Cleavage of proBDNF by tPA/plasmin is essential for long-term hippocampal plasticity. Science 306: 487-491, 2004.

43. Hellmich HL, Garcia JM, Shimamura M, Shah SA, Avila MA, Uchida T, Parsley MA, Capra BA, Eidson KA, Kennedy DR, Winston JH, DeWitt DS and Prough DS: Traumatic brain injury and hemorrhagic hypotension suppress neuroprotective gene expression in injured hippocampal neurons. Anesthesiology 102: 806-814, 2005

44. Sairanen M, Lucas G, Ernfors P, Castrén M and Castrén E: Brain-derived neurotrophic factor and antidepressant drugs have different but coordinated effects on neuronal turnover, proliferation, and survival in the adult dentate gyrus. J Neurosci 25 : 1089-1094, 2005.

45. Suzuki A, Fukushima H, Mukawa T, Toyoda H, Wu LJ, Zhao MG, Xu H, Shang Y, Endoh K, Iwamoto T, Mamiya N, Okano E, Hasegawa S, Mercaldo V, Zhang Y, Maeda R, Ohta M, Josselyn SA, Zhuo $M$ and Kida S: Upregulation of CREB-mediated transcription enhances both short- and long-term memory. J Neurosci 31: 8786-8802, 2011.

46. Han QQ, Jin W, Xiao ZF, Huang JC, Ni HB, Kong J, Wu J, Chen B, Liang WB and Dai JW: The promotion of neurological recovery in an intracerebral hemorrhage model using fibrin-binding brain derived neurotrophic factor. Biomaterials 32: 3244-3252, 2011. 